
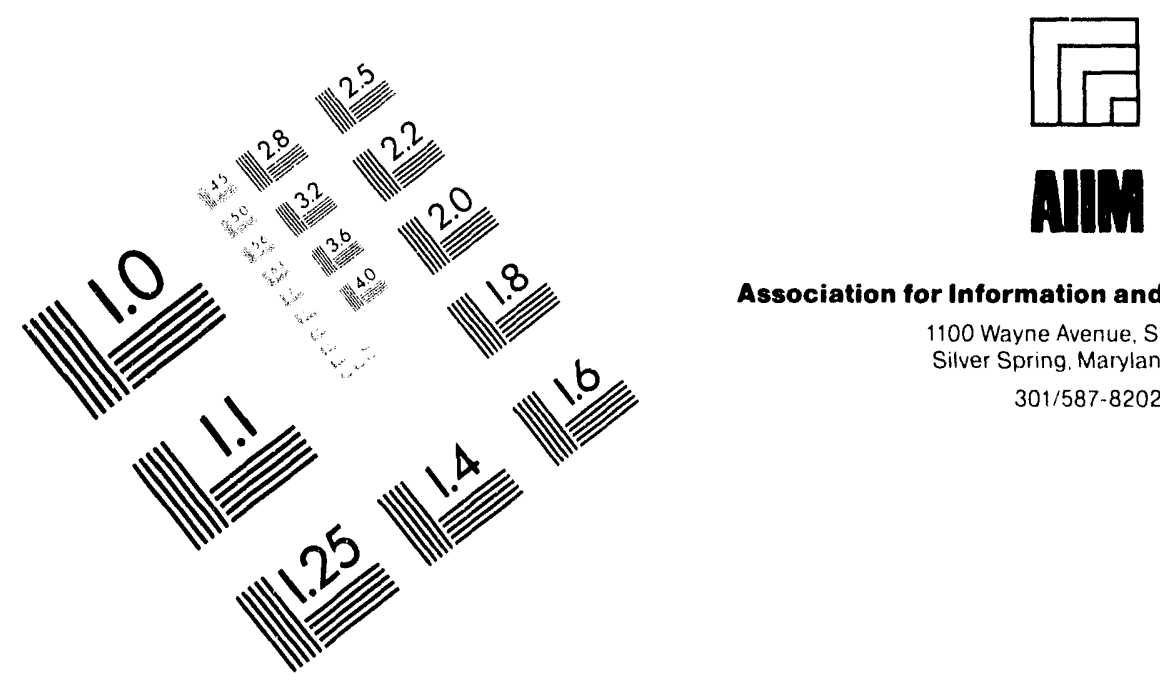

Association for Information and Image Management

1100 Wayne Avenue, Suite 1100

Silver Spring. Maryland 20910

301/587-8202

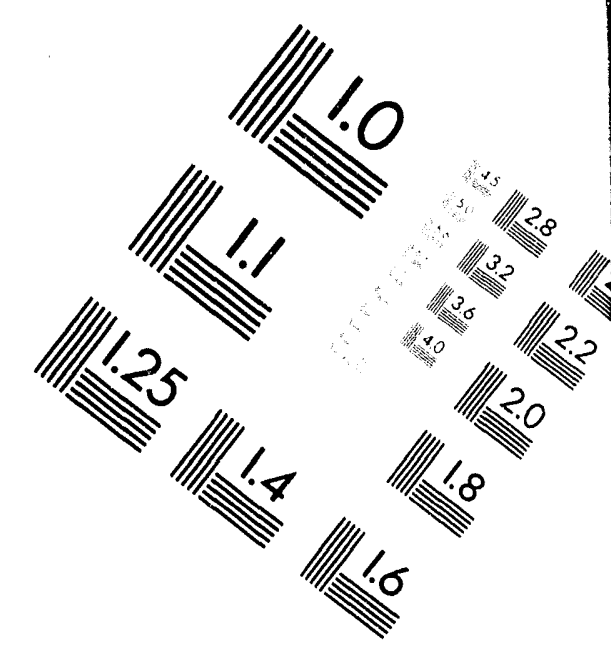

Centimeter

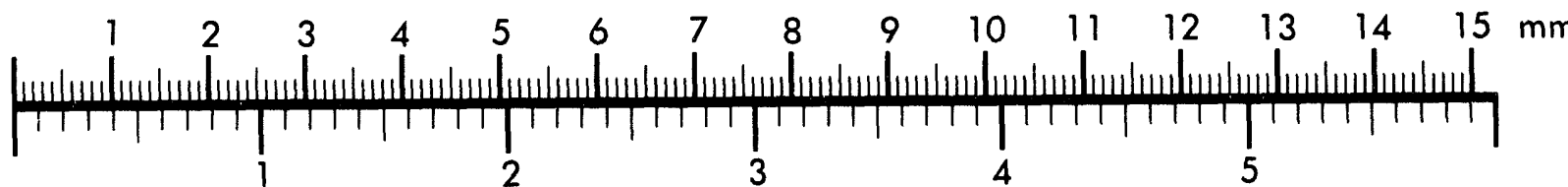

Inches

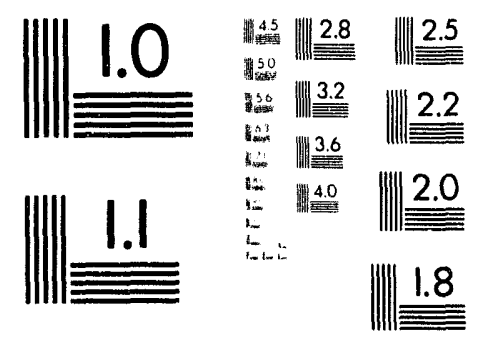

$\|\underline{\underline{\underline{\underline{\underline{x}}}}}\| \underline{\underline{\underline{\underline{1}}}} \| \underline{\underline{\underline{\underline{6}}}}$

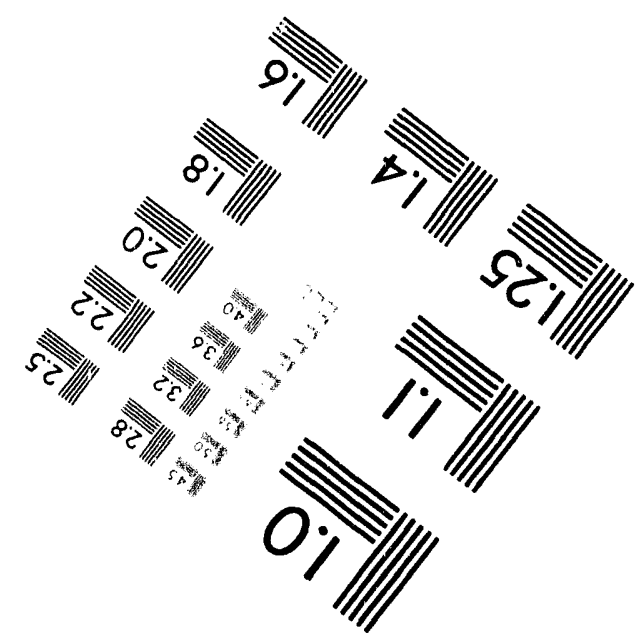

MANUFACTURED TO AIIM STANDARDS

BY APPLIED IMAGE, INC.

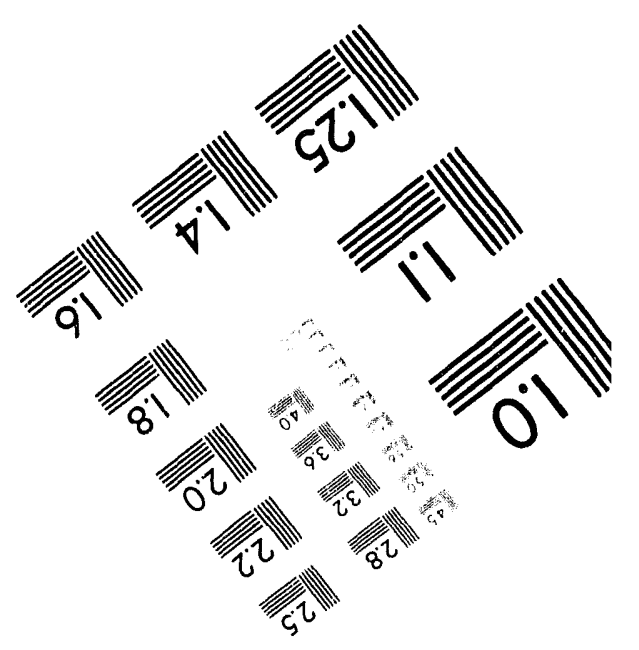



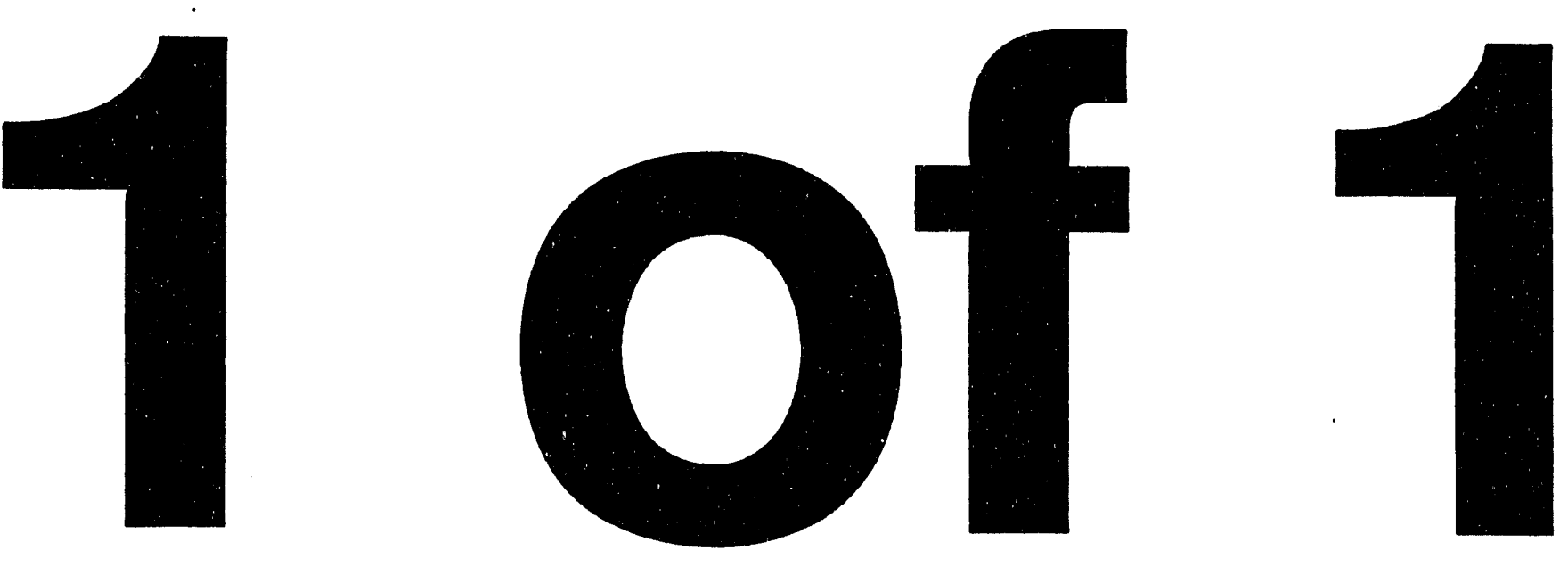
$12 / 1 / 127-9485(1)$

\title{
Exploratory Study on H13 Steel Dies
}

\author{
Anne J. Sunwoo \\ Anne J. Sunwoo
}

UCRL-ID-117158

April 1994

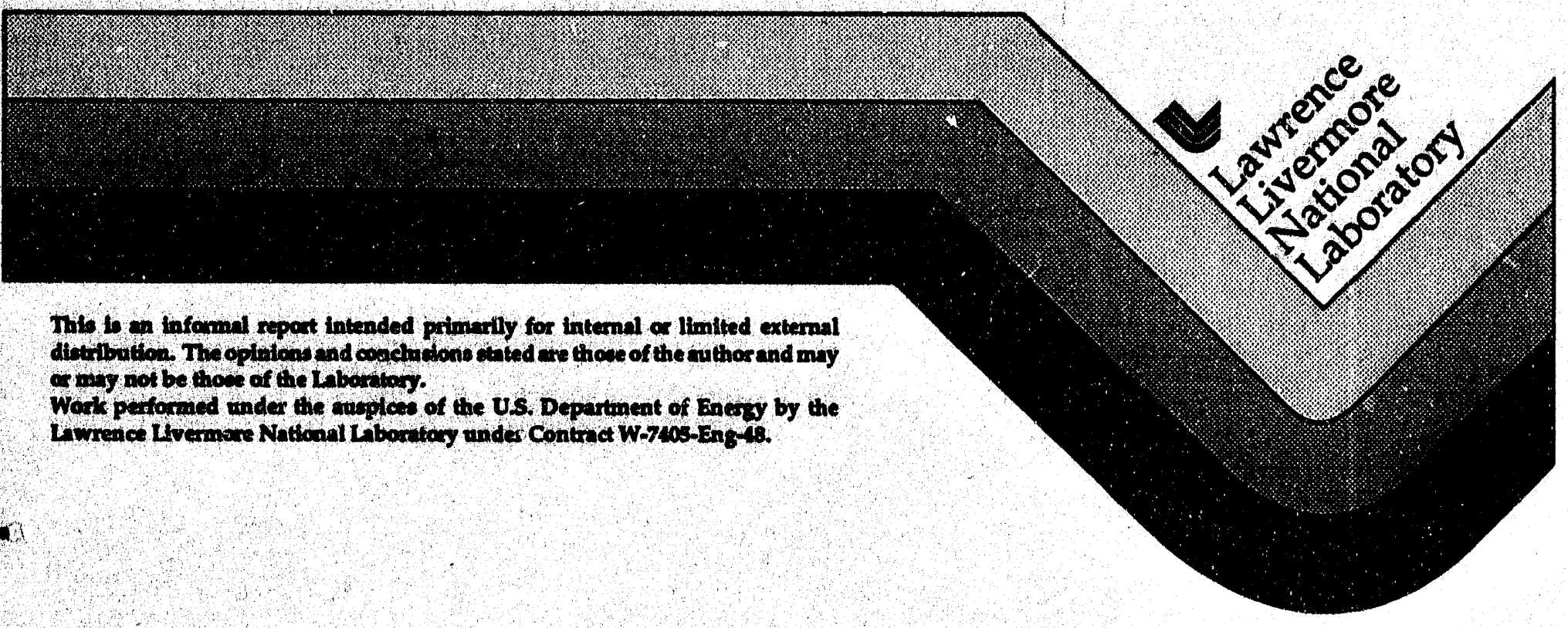




\section{DISCLAIMER}

This dacument was prepared as an scoount of work sponsored by an agency of the United States Government. Neither the United States Government not the University of Culfornia nor any of their employees, makes any Warranty, express of limpiled, or aseumes any tegal llability or responsibility for the sccuracy, completeness, or usefulaten of any iaformation, apparatus, product, or process disclosed, or represents that its use would not Infinge privately owned rights. Reference herein to any specific coenmercial products, proces, or service by tride bane, trademark, mamuf ceturer, or otherwise, does not necesearily constitute or imply its endorsement, recosmendation, or favoring by the Uhited States Goverament or the Ubiversity of Calffornia. The views and oplaiows of authors expresed hereln do not necessarily stale or reflect those of the United States Government or the Uativerity of Californis, and stall not be used for advertising or product endorsenent purposes.

This report bas been reproduced directly from the beat avaliable copy.

Available 10 DOE and DOE contractors froen the Onice of Scientinc and Techaical Information P.O. Bax 62, Oak Bidge, IN 37831

Prices avalible from (615) 576-8401, FTS $626-8401$

Avallable to the public from the National Techaleal Information Service

US. Departenent of Commerce 5285 Port Royal RA. Springhed VA 20161 


\title{
Exploratory Study on H13 Steel Dies
}

\author{
Anne J. Sunwoo \\ University of California \\ Lawrence Livermore National Laboratory \\ Livermore, CA 94550
}

\section{Introduction}

Ultrahigh-strength $\mathrm{H} 13$ steel is a recommended die material for aluminum (Al) die casting [1]. The steel is hot-worked and air-hardened to produce a martensitic microstructure, which in turn provides good resistance to softening and to thermal fatigue. Chromium and vanadium are added to the steel to increase resistance to high temperature oxidation, corrosion, and erosive wear. Other beneficial characteristics of the steel include ease of forming, good wela'ability, relatively low coefficient of thermal expansion and acceptable thermal conductivity. These attributes are important in die materials because the performance of dies is directed related to being able to withstand the erosive action of molten $\mathrm{Al}$ under high injection velocity, and to thermal gradients within the dies and frequency of exposure to high temperature. Because the steel is well-adapt to these conditions, dies made from $\mathrm{H} 13$ steel can be safely water-cooled during hot working operations without cracking.

However, after time in service the qualities reported for this material were not maintained. Instead, the dies exhibited severe surface cracking and excessive wear. Figure 1 shows a section of a die where the service life was shortened due to extensive surface cracking. In addition to surface cracking problems, there is also a problem with erosive wear in the die caused by the high pressure injection of molten Al. These problems lead to expensive repair and replacement costs. Hence, an exploratory study was initiated to investigate the causes for surface cracking of $\mathrm{H} 13$ dies.

\section{Experimental Procedure}

Microstructural characterization was performed on small sections of the as-received die. The samples were polished in the through-thickness direction using a standard polishing 
technique. Both optical and scanning electron microscopy (SEM) were employed to characterize the polished and fracture surfaces. Rockwell C Hardness (HRC) measurements were taken from the outer and inner surfaces of the die.

A quench study was performed to qualitatively simulate the thermal cycle. The sample was heated to $1200^{\circ} \mathrm{F}\left(676.7^{\circ} \mathrm{C}\right)$ (the temperature at which a molten $\mathrm{Al}$ is used in the plant), for one minute and water quenched. Thermal cycling was repeated for 35 times, while monitoring the polished surface every fifth cycle for any surface changes.

\section{Results and Discussion}

The composition of $\mathrm{H} 13$ steel in wt-\% is $0.4 \mathrm{C}-0.5 \mathrm{Mn}-1.0 \mathrm{Si}-5.0 \mathrm{Cr}-1.5 \mathrm{Mo}-1.0 \mathrm{~V}-$ bal. Fe. The sulfur content in $\mathrm{H} 13$ is limited to no more than 0.04 wt-\%, which is an innocuous amount if the sulfides are homogeneously distributed in the steel as spheroidized particles. However, because the $\mathrm{H} 13$ steel has been heavily hot worked, the resulting morphology of sulfides is stringers aligned in the rolling direction. Since there is high surface energy associated with these high aspect ratio stringers, they provide a preferential crack path into the die. Figure 2 shows a cross-sectional view of a crack following the stringer and its fracture surface. Cracks can also propagate along the weakest interface in both an intergranular as well as a transgranular mode (Figure 3). Moreover, the resistance to fracture of the steel is greatly compromised due to the presence of the stringers. In Figure $4 \mathrm{a}$, the fracture surface reveals a uniform distribution of the stringers, and because the cracks initiate externally, the crack surfaces become heavily oxidized, displaying a distinct interface (Figures $3 b$ and $4 b$ ).

Although the internally present sulfide stringers provide easy access into the interior of the die, the driving force for crack propagation is externally induced transient thermal gradient within the die which is created by the water quenching (compression)-molten $\mathrm{Al}$ injection (tension) process. As the thermal-fatigue continues, the stress intensity at the crack tip will increase, causing the crack to propagate. The effect of repeated thermal cyclic strain on the die is shown in Figure 5. The figures also reveal that corrosion plays an active role in crack initiation, starting with surface pitting. The quench test showed that after about 20 cycles, pitting occurred. 
The amount of corrosion along the surface of the cracks is inversely proportional to the depth of crack.

Loss of thermal-fatigue resistance may have been enhanced by decarburization of the die surface. The removal of carbon from the surface leads to loss of strength and the decarburized material becomes less resistant to thermal-fatigue. Figure 6 shows a partially decarburized surface layer from the as-received die sample. The suggested hardness range for $\mathrm{H} 13$ die material used for $\mathrm{Al}$ die casting is between 44-48 $\mathrm{HRC}$, which is equivalent to about $230 \mathrm{ksi}$ tensile strength [2]. The hardness measurements showed that the overall hardness of this die was lower than the suggested hardness and that the exposed surface had slightly lower hardness of about 41 HRC than the unexposed surface hardness of about $42 \mathrm{HRC}$, which is a minimum of 20 ksi lower in strength. Thus, the decarburized surface from high temperature exposure in a unprotected atmosphere may have some effect on the difference in the hardness. In the die casting environment, the die surfaces will continue to decarburize, losing their desirable surface properties.

\section{Recommendations}

The results of this exploratory investigation suggest that surface cracking is caused by interrelated factors, internal to the die material as well as externally induced conditions. If the results are confirmed, then changing the morphology of sulfides from stringer to spheroidized particles may eliminate a preferential crack path into the die and improve resistance to surface cracking [3]. The morphology of the sulfide inclusions can be controlled by the cooling rate [4], the extent of hot reduction [5], and the post-deformation heat treatment [6].

Externally, decreasing the thermal gradient, i.e. lessening the effects of thermal-fatigue, will reduce the stress intensity at the crack tip, which hinders crack propagation. Moreover, protecting the die surface will prevent decarburization and thereby minimizes the loss of surface strength and of resistance to thermal-fatigue, corrosion, and oxidation. For example, nitriding the die will provide a protective layer as well as a highly wear resistant surface [1]. 


\section{Acknowledgments}

The author would like to thank Drs. E.N.C. Dalder and R.R. Vandervoort at LLNL and J.W. Chan at Lawrence Berkeley Laboratory for reviewing the manuscript, and Mr. J.L Ferreira at LLNL for sample preparation and micrographs.

\section{References}

1. ASM Metals Handbook, vol. 1, 441, 10th ed., Materials Park, OH 44073.

2. Wilson Conversion Chart, Page-Wilson Corporation, 929 Connecticut Ave. Box 9021 , Bridge, CT 06602.

3. I.M. Wolff and A. Ball, Mate. Sci. Tech., vol. 7, 1991, 520.

4. P.P. Mohla and J. Beech, J. Iron Steel Inst., vol. 2, 1969, 177.

5. Y. Tomita, Metall. Tans. A, 19A, 1988, 1555.

6. Y.V. Murty, Metall. Trans. A, 6A, 1975, 2031. 


\section{Figure Captions}

Figure 1. Section of H13 steel die: a) low magnification; b) higher magnification showing erosion around the hole. The service life was shortened due to severe surface cracking problems.

Figure 2. SEM micrographs: a) a cross-sectional view of a crack following the sulfide stringer; b) corresponding fracture surface showing crack path into the die through sulfide (dark region).

Figure 3. Optical inicrographs showing crack propagation into the die by following the weakest interface: a) between the stringers and the matrix; b) in an intergranular and a transgranular mode.

Figure 4. SEM fractographs: a) a low magnification view of fracture surface showing a uniform distribution of sulfide stringers; $b$ ) the oxidized surface represents previously cracked surface.

Figure 5. Optical micrographs: a) a surface view showing the effect of repeated thermal cyclic strain on the die; b) a cross-sectional view showing the effect of corrosion enhanced crack opening.

Figure 6 . Optical micrograph showing a partially decarburized surface layer from the asreceived die sample. 

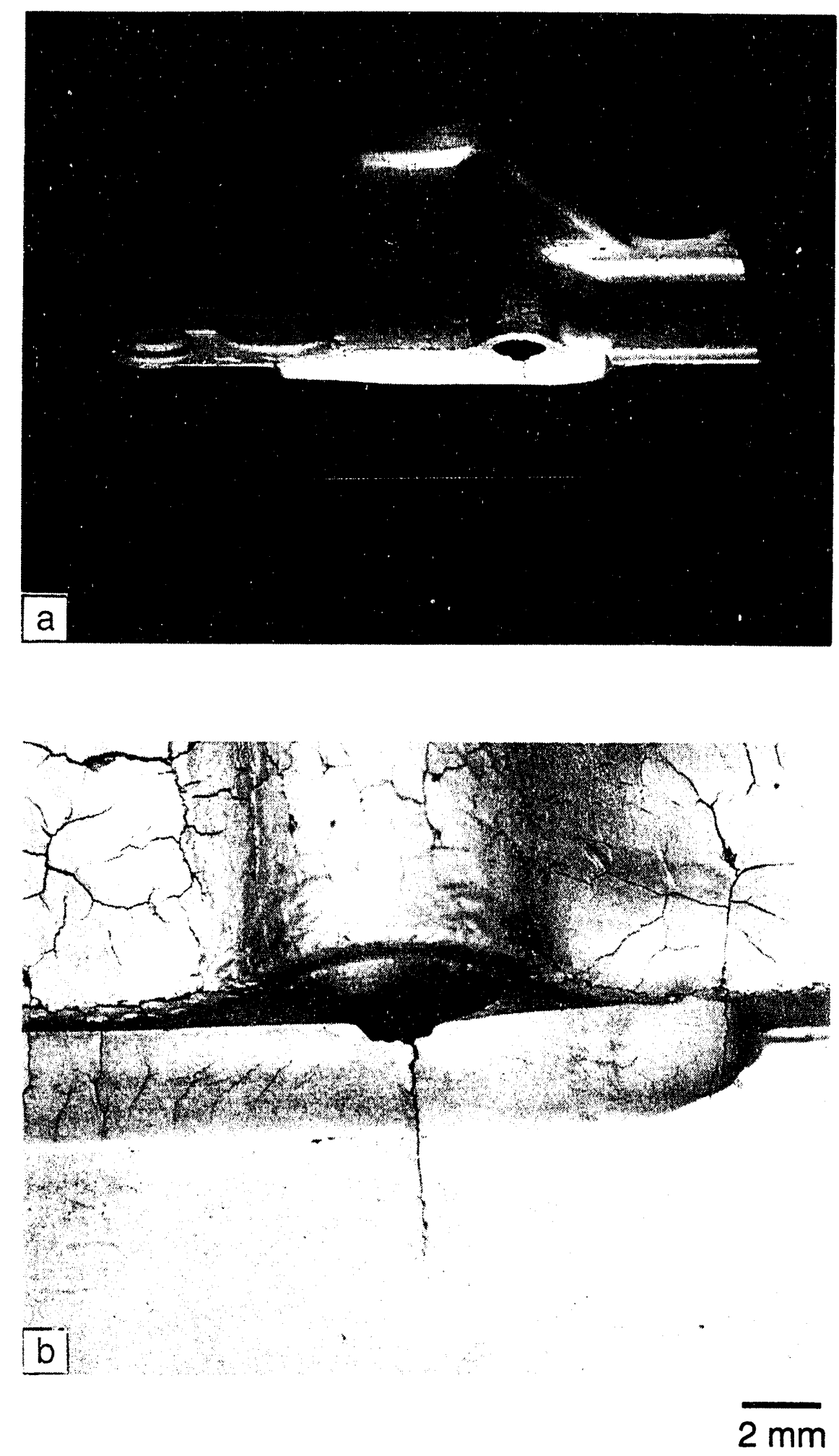

Figure 1 

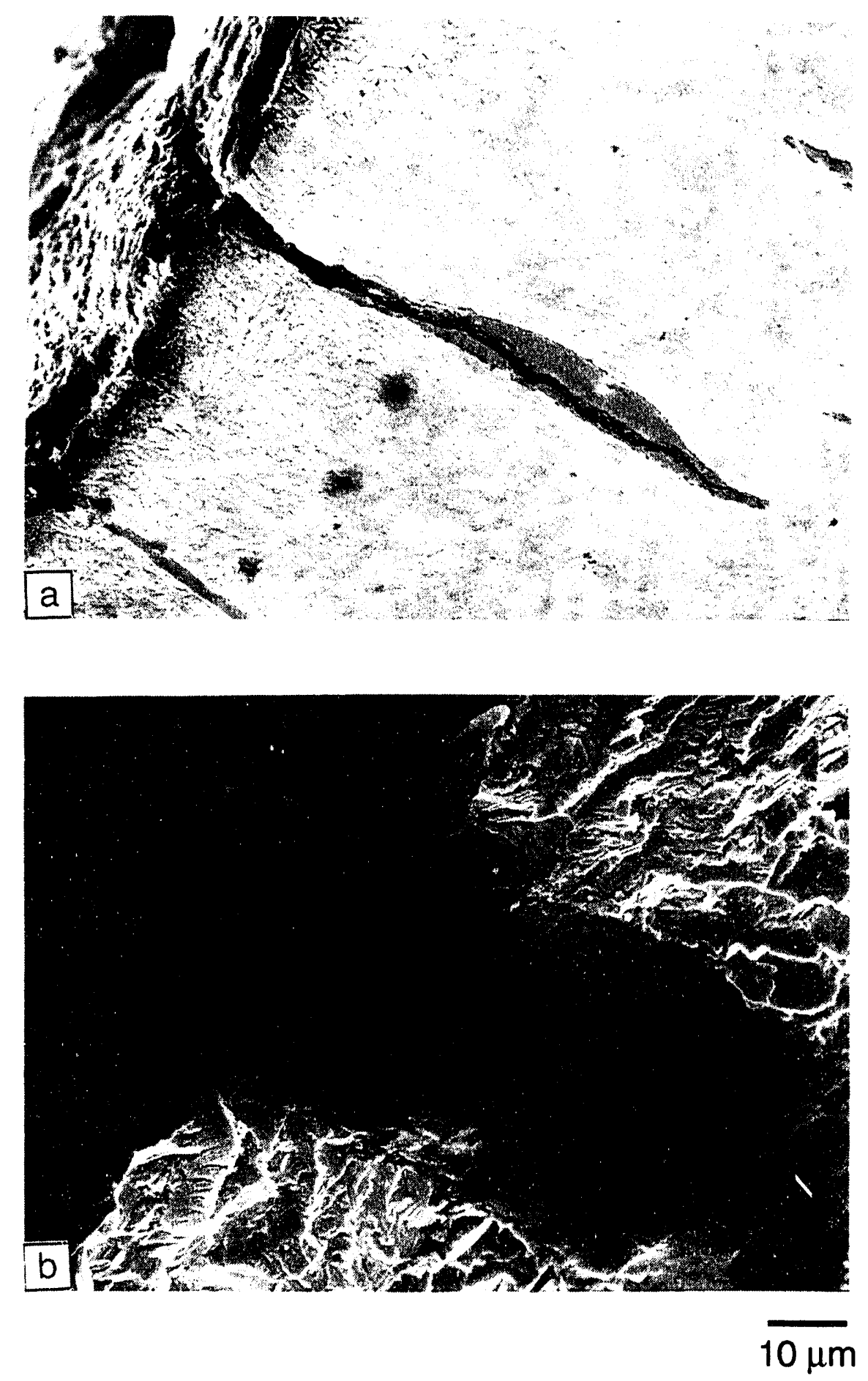

Figure 2 

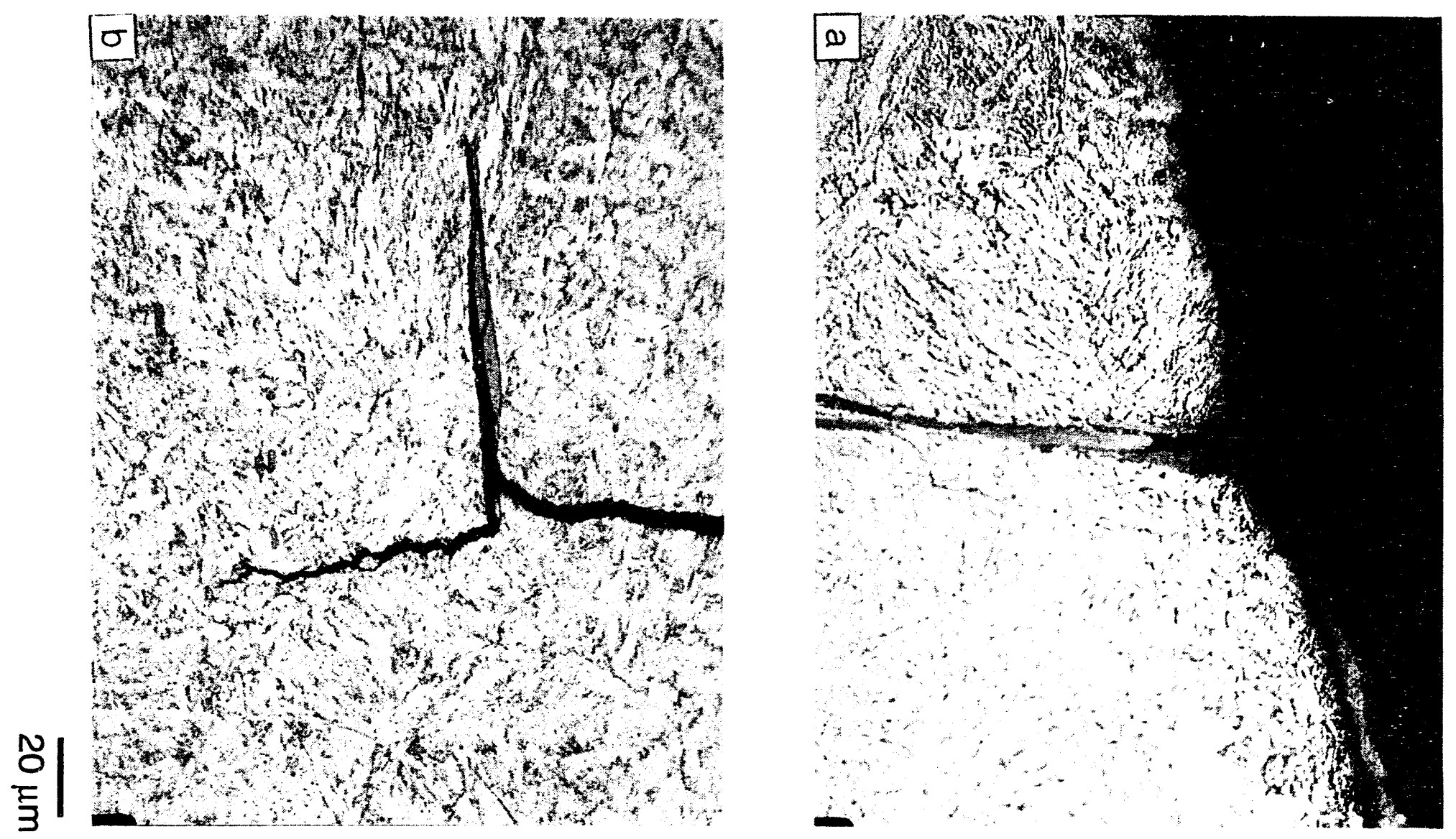
T!
0
0
0
0
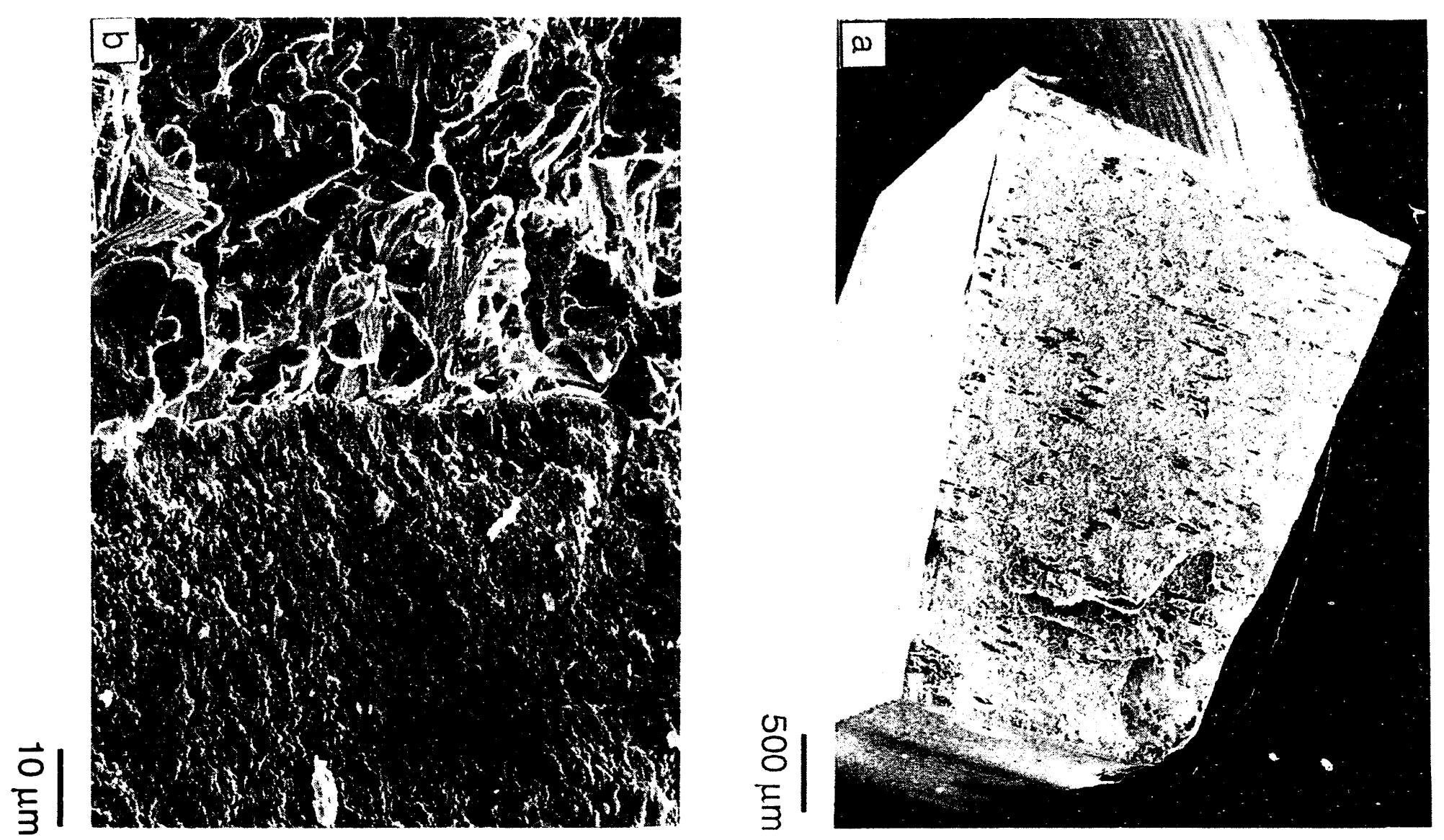
url 00t

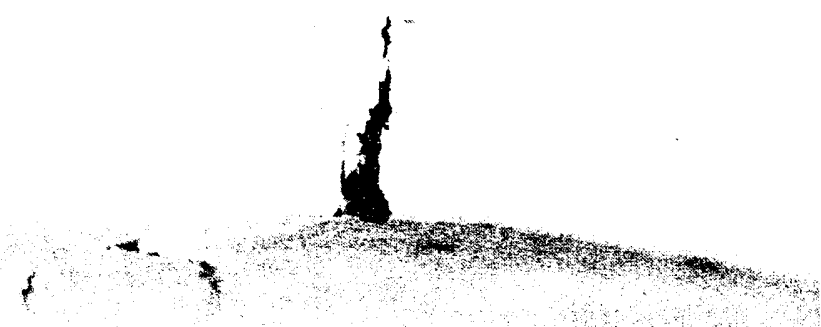

mul

q

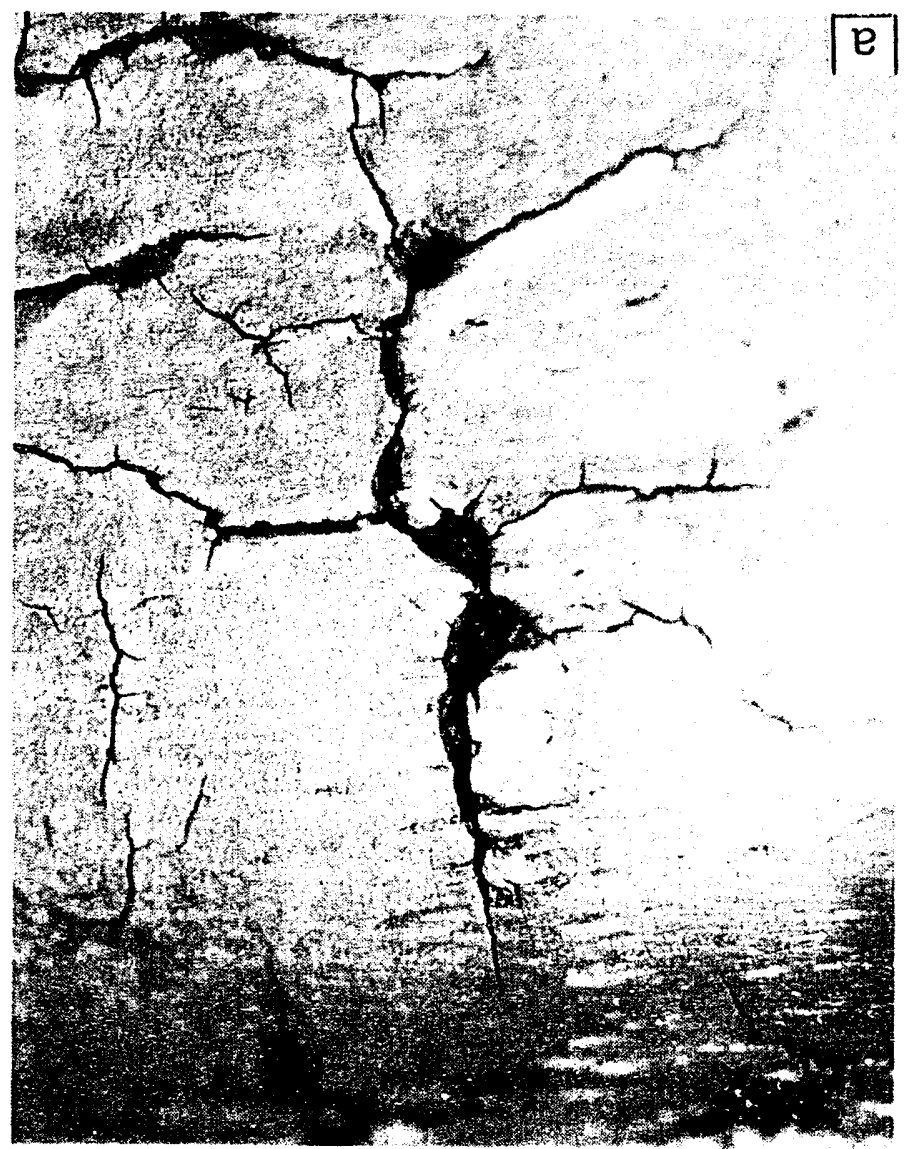




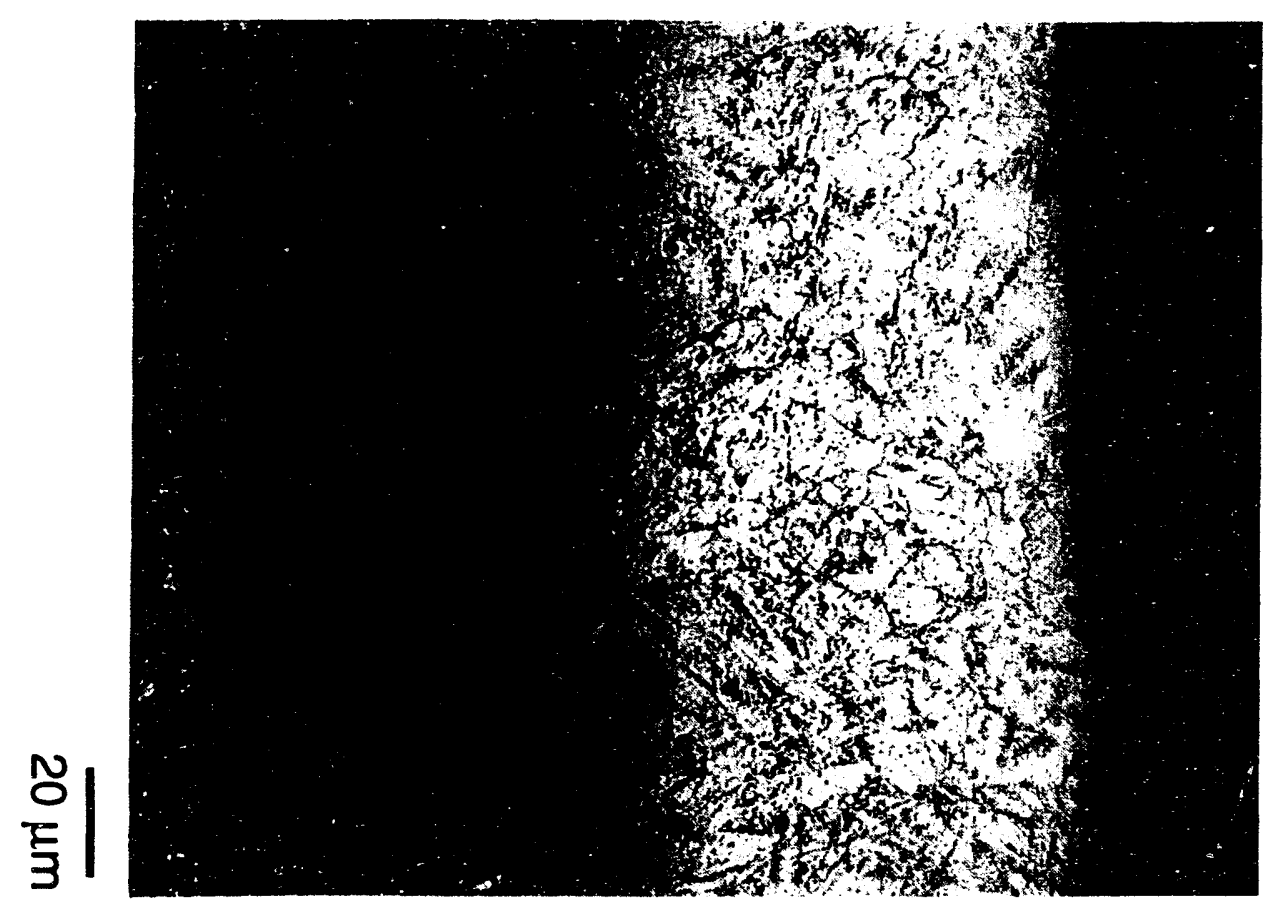



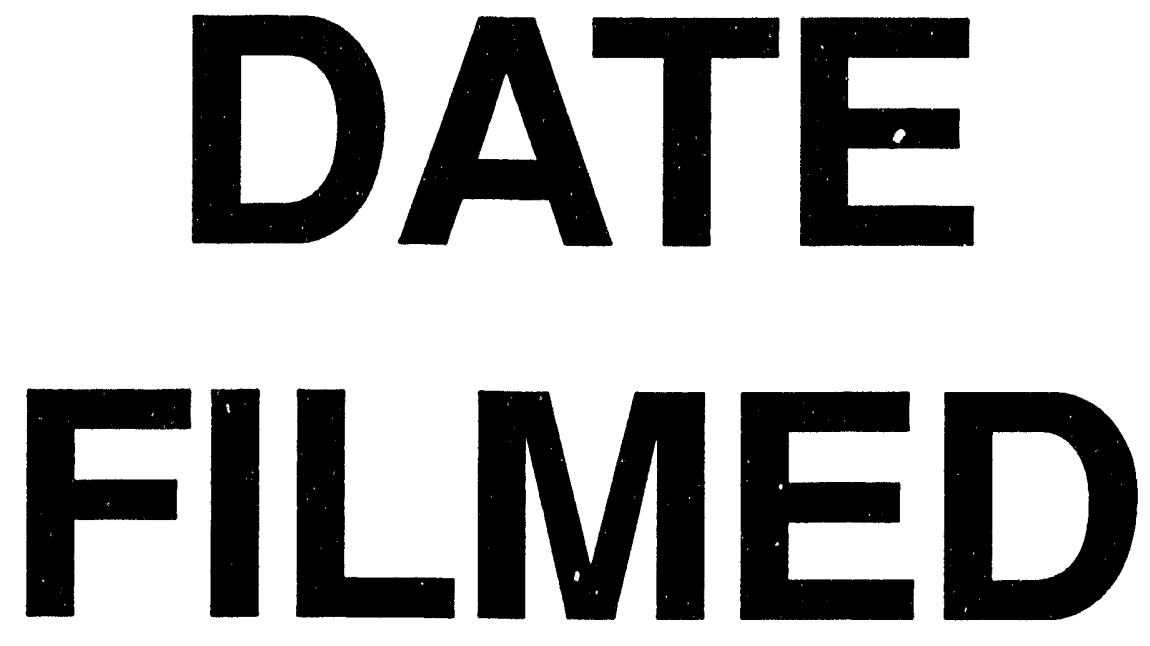

$6 / / 6 / 94$
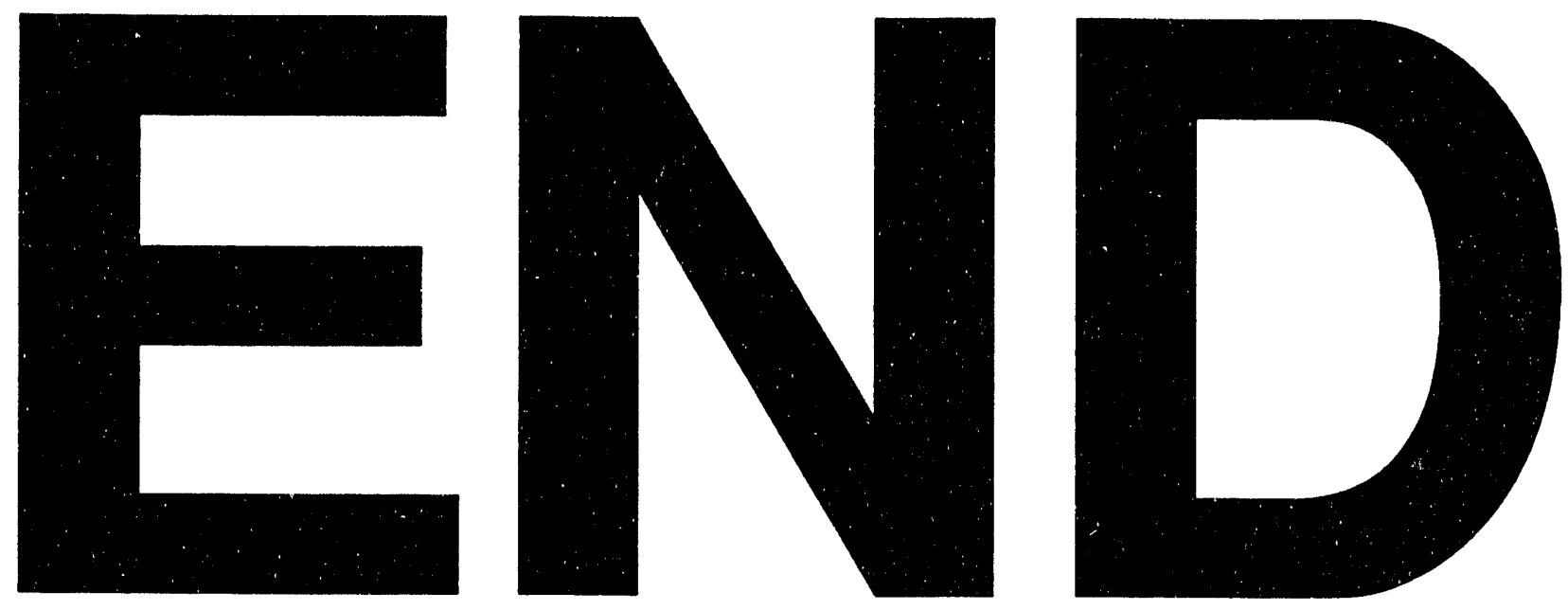
